\title{
Analysis of the Innovative Drugs Market from the Aspect of Heng Rui
}

\author{
Jiali Chen ${ }^{1, *}$ \\ ${ }^{1}$ IBSS, Xi'an Jiaotong-Liverpool University, Suzhou, Jiangsu, China, 215123 \\ *Corresponding author. Email: Jiali.Chen19@student.xjtlu.edu.cn
}

\begin{abstract}
It is currently thought that the innovative drug sector has played a critical role in the listing and financing of high-tech firms. Affected by the outbreak of coronavirus pandemic, China's pharmaceutical companies are expected to soar even more spectacularly, therefore this kind of pharmaceutical firms' investment value recognition has generally attracted attention from the venture investment organizations. However, traditional enterprise valuation methods, such as relative valuation methods and the price - earnings ratio, often find it difficult to fully reflect the intrinsic value of the companies. This paper analyzes the current market trend and establishes a DCF model of the Heng Rui Pharma whose valuation result has some reference significance to innovative drugs market. During this analysis process, the statistics from the Wind and the financial statements can be processed logically with the aid of Excel and graphic program. The results demonstrate that Heng Rui Pharma is worth to investors in the long run, but it is not recommended to be heavily invested in. The results also have implications for understanding that the innovative drugs market is one of few the diamond grade track.
\end{abstract}

Keywords : Innovative drug; Heng Rui; DCF model; Enterprise value assessment

\section{INTRODUCTION}

A sudden Corona Virus epidemic quickly swept China in 2020, and fortunately this "defense war" finally achieved a success under the common efforts of the medical workers. According to Business Wire, Chinese government stressed the pivotal status of the innovative drugs in the treatment of the patients and encouraged the further study of the new medicine [1]. While a variety of definitions of the term new medicine have been suggested, this paper will use the definition suggested by Nakao, Minato and Uemoto, who saw it as the medicine that has the innovative chemical construction or new therapeutic use [4]. This track has attracted worldwide attention and becomes the target of competition in the capital market, so there is a great necessity for investors to confirm whether it really owns the investment value. The essay is intended to analyze the investment value of the innovative drugs market from the perspective of the Heng Rui Pharma. Therefore, the essay has been divided into four parts. The first part deals with the analysis of the pharmaceutical sector and the representative of the innovative medicine company. Then, the second part is concerned with the methodology used for the study.
Also, it will be explained that why the DCF model will be used to analyze the innovative drugs market. Thirdly, Heng Rui pharmaceutical will be taken as an example, and this essay compares the results of the DCF model evaluation with the company's market value analysis to verify the applicability of the DCF model in evaluating the value of innovative pharmaceutical companies. The final part will summarize the main results and put forward corresponding suggestions and the prospect for the application of the model.

\section{ANALYSIS OF THE INDUSTRY AND THE FIRM}

Pharmaceutical industry is reputed as "Sunrise Industry", and has a broad market owing to its characteristics and the external environment. Firstly, pharmaceutical industry owns a great anti-cyclical risk ability. Pharmaceutical industry belongs to the fast-moving consumer goods industry (FMCG), but it is different from the general FMCG industry. It is known that in the general FMCG industry, consumers have the full right to select the goods on their own, and assume full payment obligations. While health care is not a full choice of consumers, nor need to assume the full 
obligation to pay. Because if people get ill, they must be treated. Thus, the whole pharmaceutical industry presents a weak cycle, and has a good anti-cyclical risk ability. Secondly, the efficiency requirements are higher than the brand requirements. Medicine is an essential substance for the prevention and treatment of human and livestock diseases, and new medicines can be sorted by natural and synthetic medicines. It can help people prevent disease, cure disease, reduce pain, improve health, and enhance the body's resistance to disease as well. The most important thing to a successful drug enterprise is the effectiveness rather than the brand. Pharmaceutical companies are not trying to cultivate consumer loyalty, they are trying to gain market share by solving consumers' problems instead. In other words, who has mastered the curative effect, who has mastered the opportunity first, whose curative effect is irreplaceable, who will lead the market. Thirdly, the government policies promote the development of new medicine. It is said that China's drug administration department has introduced a series of related policies, such as accelerated approval of innovative drugs, drug marketing authorisation system (MAH) and chemical drug registration classification reform, which have greatly raised the barrier of the innovative drugs market and promised bright development prospect [2]. Besides, according to the $\mathrm{Wu}$ et al, pharmaceutical innovation, as one of the most profitable fields in the whole pharmaceutical business, whose average gross profit rate is nearly $70 \%$ and this figure far exceeds that of generic drug and bulk drug [6]. It is the main direction of the development of China's pharmaceutical industry in the future.

Moreover, Jiangsu Hengrui Pharmaceuticals is the leading company of the Chinese innovative drug industry, since it has high profitability and put large $\mathrm{R} \& \mathrm{D}$ investment in innovative drug sector. It is a global pharmaceutical enterprise engaged in research and development, production and sales, whose various product pipelines involve anti-tumor drugs, surgical anesthesia drugs, special han fluid, contrast agents, cardiovascular drugs and many other fields [5]. On the one hand, the company ensures high profitability. For example, in 2020, the net profit of Heng Rui Pharmaceutical reached 6.328 billion yuan, ranking the first in the industry and even much higher than the second place Fosun Pharmaceutical. It accounted for approximately $46 \%$ of the industry profit. Additionally, the average growth rate in 10 years was $23.92 \%$, which was also much higher than the industry growth rate. The growth rate of net profit was even more exaggerated in 2015, which approached $45.05 \%$. With $8.6 \%$ of the industry revenue, it has created $46 \%$ of the industry profit, and the annual revenue and profit growth rate is stable at more than $20 \%$. From these figures, we can conclude that Heng Rui Pharmaceutical possesses strong and stable cash flow. On the other hand, the company has laied more emphasis on the endogenous growth of enterprises and the ability of independent research and development. It provides a steady stream of cash flow to feed the research and development business, in order to master the opportunity first. The strong R \& D capability corresponds to the high annual $\mathrm{R} \& \mathrm{D}$ expense of Heng Rui Pharmaceutical, which has also increased year by year, from 1.759 billion yuan in 2017 to 4.989 billion yuan in 2020. The revenue ratio has increased from $12.71 \%$ to $17.99 \%$, which is almost twice as high as that of Fosun Medicine in the same innovative drug field. What's more, Tong claimed that in order to reach the requirements of FDA for product lifecycle management, the company has hired world-class quality control experts and established six GMP management systems [5]. Thus, the company's innovative drug board has entered matured field. Every year, innovative drugs are applied for clinical application, and every 1 to 2 years, innovative drugs are listed on the market. It can be visible to the naked eye that the early investment in innovative drug's research and development has gradually entered the harvest period.

To conclude, Heng Rui Pharmaceutical has a great operating condition, rapid development speed, rich products pipelines, strong profitability, strong R\&D capability, and strong support from government policies, so it has a broad development space and can be selected as the representative of the Chinese innovative drug enterprises.

\section{METHODOLOGY}

Through the research in $\mathrm{Wu}$ et al 's paper, it is believed that in order to reasonably evaluate the value of the innovative drug companies, it is necessary to establish a matching evaluation system [6]. Based on the characteristics of the innovative drug companies, like high investment, high profitability and high risk, this paper attempts to utilize the DCF model to evaluate the value of this type of corporation. Because it is regarded as the most traditional and penetrating valuation method [3]. The high $\beta$ of the cyclical stocks makes their recent cash flow very high, while the low beta and sustainable growth of the pharmaceutical stocks also makes the analysis of their long-term cash flow even more important. Although DCF valuation model is not suitable for the individual stock research of A-shares at present, it can be explored and experienced to provide some inspiration. Kte and $\mathrm{Pi}$ defined discounted cash flow (DCF) as a valuation method employed in the capital market, which is established to determine the value of that investment [3]. Additionally, the underlined idea of the DCF model is to discount equity cash flows with the cost of equity capital, in order to get the value of shareholders' equity, and then discount free cash flows with the weighted average cost of capital to 
get the value of the entire company. During the process of applying DCF model, the factor like estimated cash flow, discount rate, and the profit duration of the enterprise is required. The following will explore the specific ideas of DCF model in innovative drug industry valuation.

In the DCF model valuation, several important parameters need to be decided first. Initially, fixed discount rate is a key factor that cannot be ignored. According to field research and financial statement analysis, the average weighted cost of capital (WACC) of this company is about $8.6 \%$. However, the data is too much higher than the other high growth industries, so the discount rate is set at $6 \%$ in the essay conservatively. In addition to the fixed discount rate, sustainable growth rate is another critical element. According to the general law of the industry and the bright prospect of the innovative drug market, it is more appropriate to set the sustainable growth rate as $5 \%$.

After the assumption, the various values can be estimated based on the law of the formula: $\mathrm{PV}=\mathrm{FCF} *$ $(1+\mathrm{g}) /(\mathrm{r}-\mathrm{g})$, where $\mathrm{r}$ is the discount rate and $\mathrm{g}$ is the

Table 1 Free Cash Flow in the previous 11 years and in the future 10 years perpetuity growth rate. After calculating the value of the perpetuity, according to the formula shown below, the final valuation of the Heng Rui enterprise and the price per share can be calculated.

$$
\mathrm{p}=\sum_{t-1}^{n} \frac{C F_{t}}{(1+r)^{t}}
$$

\section{RESULTS AND DISCUSSION}

To begin with, the equation of linear regression can be calculated based on the FCF (Free Cash Flow) in the past 11 years. From the earnings report of Heng Rui, it can be found that the FCF is 0.99 billion yuan, -0.13 billion yuan, 4.92 billion yuan, 9.12 billion yuan, 12.76 billion yuan, 18.83 billion yuan, 14.82 billion yuan, 21.76 billion yuan, 22.45 billion yuan, 32.55 billion yuan and 28.78 billion yuan from the year 2010 to 2020 (Table 1). Therefore, the equation $\mathrm{y}=3.1765 \mathrm{x}-3.8993$ can be developed by means of these related analysis data (Figure 1).

\begin{tabular}{|c|c|c|c|c|c|c|c|c|c|c|c|}
\hline Sub ject Year & 2010 & 2011 & 2012 & 2013 & 2014 & 2015 & 2016 & 2017 & 2018 & 2019 & 2020 \\
\hline FCF in the previvus 11 Yro billins & 0.99 & -0.13 & 4.92 & 9.12 & 12.76 & 18.83 & 14.82 & 21.67 & 22,45 & 32.55 & 28.78 \\
\hline Subject Year & - & 2021 & 2022 & 2023 & 2024 & 2025 & 2026 & 2027 & 2028 & 2029 & 2030 \\
\hline FCF in the fiture 10 Yrs billinss) & - & 31.04 & 34.22 & 37.4 & 40.57 & 43.75 & 46.93 & 50.1 & 53.28 & 56.46 & 59.63 \\
\hline
\end{tabular}

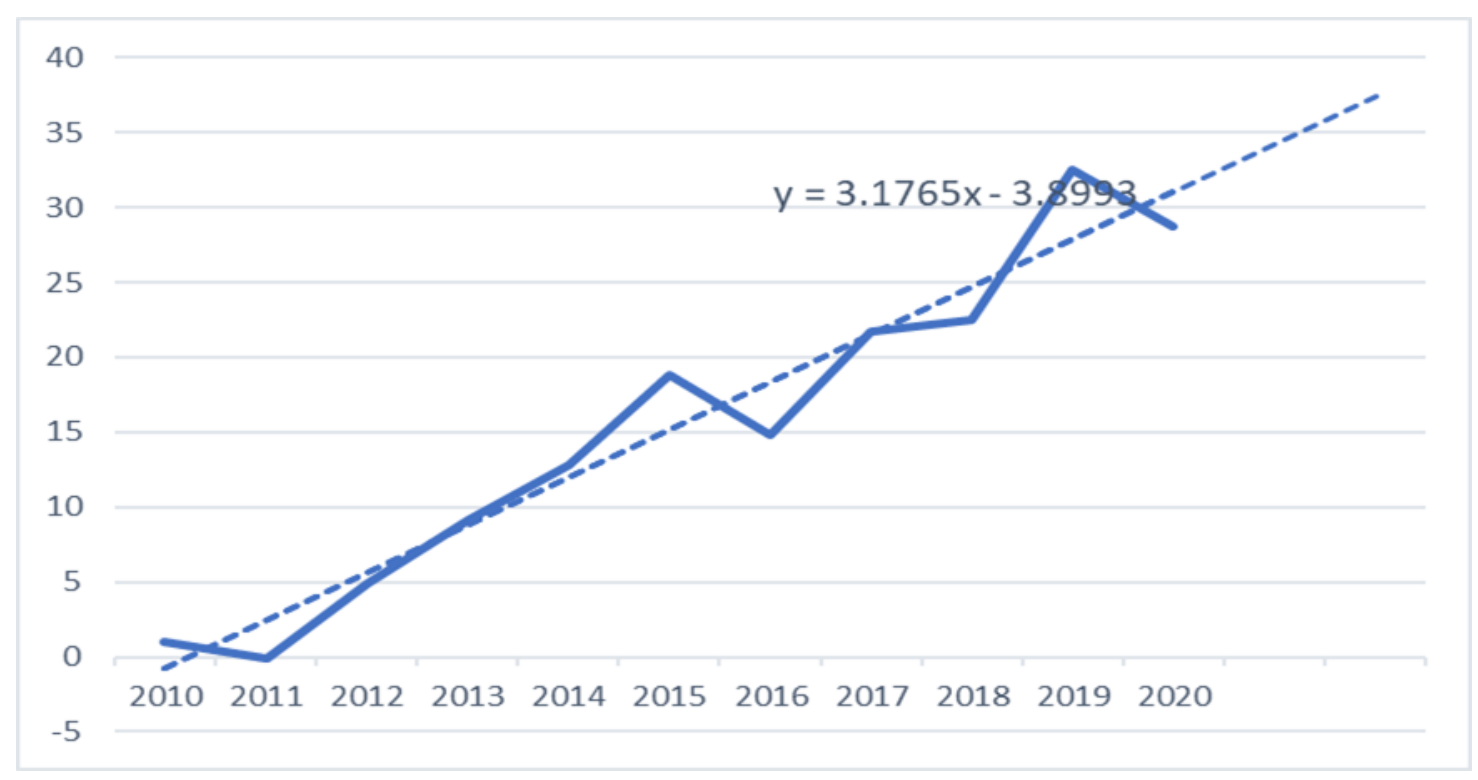

Figure 1 Linear Regression Equation of the Free Cash Flow

As the data shown in the table below, the FCF in the future 10 years can be estimated, and the number is 31.04 billion yuan, 34.22 billion yuan, 37.4 billion yuan, 40.57 billion yuan, 43.75 billion yuan, 46.93 billion yuan, 50.1 billion yuan, 53.28 billion yuan, 56.46 billion yuan and 59.63 billion yuan, respectively. Secondly, based on the assumption, discount the FCF in the future 10 years by the commutation factor $(1+r)^{\wedge} n$, in which $r$ 
means the discount rate of $6 \%$ and $\mathrm{n}$ means the discount discounted FCF (Table 2). period. 322.51 billion yuan is the total annual

Table 2 Annual discounted Free Cash Flow

\begin{tabular}{|c|c|c|c|c|c|c|c|c|c|c|}
\hline Sub ject/Year & 2021 & 2022 & 2023 & 2024 & 2025 & 2026 & 2027 & 2028 & 2029 & 2030 Total \\
\hline CF in the future 10 Yrs (bilins) & 31.04 & 34.22 & 37.4 & 40.57 & 43.75 & 46.93 & 50.1 & 53.28 & 56.46 & 59.63 \\
\hline omm utation factor & 1.06 & 1.12 & & 1.26 & & & 1.5 & 1.5 & & 1.79 \\
\hline Annuald iscounted FCF billinss) & 29.29 & 30.45 & 31.4 & 32.14 & 32.69 & 33.08 & 33.32 & 33.43 & 33.42 & 33.3 \\
\hline
\end{tabular}

Thirdly, calculate the perpetuity value and discount the perpetuity value (PV) by growth rate of the perpetuity $(\mathrm{g}) 5 \%$.

$$
\begin{aligned}
& \mathrm{PV}=\mathrm{FCF} 10 *(1+\mathrm{g}) /(\mathrm{r}-\mathrm{g})=59.63 *(1+5 \%) /(6 \% \\
& -5 \%)
\end{aligned}
$$

$$
=6261.15 \text { billion yuan }
$$

Discounted PV $=6261.15 /(1+6 \%)^{\wedge} 10$

$$
=3497.85 \text { yuan }
$$

Then, by adding the amount of total discounted FCF in 10 years of 322.51 billion yuan and the discounted PV value of 3497.85 billion yuan together, the stockholders' equity can be computed as 3820.36 billion yuan. Finally, the stockholders' equity value is divided by the number of the shares, and therefore, what the share is worth is given as 59.72 yuan.

To sum up, the owners' equity value of the Heng Rui Pharmaceuticals is evaluated as 3280.36 billion yuan, and the value of the price per share is predicted as 59.72 yuan. Therefore, the value of the Heng Rui Medicine mainly comes from sustainable growth, which means that the valuation of the Heng Rui Pharmaceuticals should be viewed from a longer term and pay more attention to the fundamentals of industry analysis based on the DCF model. However, considering today the stock price of the Heng Rui is nearly 2 times the valuation result, it is not recommended for investors to have big positions.

\section{CONCLUSION}

In conclusion, it is suggested to buy and hold the Heng Rui stock for a long time, because it has both high profitability and self-innovate capability. But it is not advised to have big positions in its equity owing to the relatively lower valuation. Besides, the innovative drug market still owns great potential and development space since it is not only the rigid demand for the people, but also possess scientific attribute. Based on the application of DCF model and comprehensive consideration of policy, market environment, self-development advantage and other factors, the essay evaluates the value of the Heng Rui Pharmaceuticals, and the overall valuation of stockholders' equity is about 3820.36 billion yuan and the price per share value is 59.72 yuan. Due to the practical constraints, the research only targeted on a simple evaluation example of Heng Rui Medicine and thus cannot provide a comprehensive review of the whole innovative drug industry. In addition, there could be some bias in the prediction of the discount rate and the perpetuity growth rate. However, such limitation will not seriously influence the evaluation result, since the essay also analyzes the fundamentals of the industry. Based on the questions raised by this study, it is recommended that additional research should focus on the in-depth analysis of the fundamentals of the industry. Moreover, future research is needed to put more effort into the evaluation of more innovative drug enterprises and will be much better to include small, medium as well as large drug firms.

\section{REFERENCES}

[1] Business Wire (English) (2020) 'China's Institute of Materia Medica Partners With Cyclica on Innovative Drug Repurposing for COVID-19', 5 March. Available at: https://search-ebscohost-com.ez.xjtlu.edu.cn/login.a spx?direct $=$ true $\& d b=$ nsm $\& A N=6 C U 92001071420$ $200305005764 \&$ site $=$ eds-live $\&$ scope $=$ site (Accessed: 19 August 2021).

[2] Chu S. et al. (2017) A review on the policy environment of innovative drug market access: A stakeholder's perspective', Chinese Journal of Health Policy, 10(8), pp. 29-33. doi: 10.3969/j.issn.1674-2982.2017.08.006.

[3] Kte, pi, B. M. (2021) 'Discounted Cash Flow (DCF)', Salem Press Encyclopedia. Available at: https://search.ebscohost.com/login.aspx?direct=true $\& \mathrm{db}=$ ers $\& \mathrm{AN}=148527001 \&$ site $=$ eds-live $\&$ scope $=\mathrm{s}$ ite (Accessed: 30 July 2021).

[4] Nakao, K., Minato, N. and Uemoto, S. (2015) Innovative Medicine. [electronic resource] : Basic Research and Development. 1st ed. 2015. Springer Japan. Available at: https://search-ebscohost-com.ez.xjtlu.edu.cn/login.a spx ?direct $=$ true $\& d b=$ cat $07934 a \& A N=x j 1.97844315$ 56510\&site $=$ eds-live $\&$ scope $=$ site $\quad$ (Accessed: 19 August 2021).

[5] Tong H. (2005) Heng Rui Medication Corporation: Building Competing Power by ERP', CHINA HEALTH INDUSTRY, (5), pp. 89-90. Available 
at:

https://search-ebscohost-com.ez.xjtlu.edu.cn/login. aspx?direct $=$ true $\& \mathrm{db}=$ edscoj\&AN=edscoj.zgwscy 2 00505029\&site $=$ eds-live $\&$ scope $=$ site $($ Accessed: 1 August 2021).

[6] Wu, X. et al. (2020) Current Situation and Analysis of Venture Capital of Innovative Medicine', Chinese Journal of Pharmaceuticals, 51(8), pp. 1070-1079. doi: 10.16522/j.cnki.cjph.2020.08.019. 